\title{
EFFECT OF CYTOKINE-INDUCED MIGRATION OF LANGERHANS CELLS ON CORNEAL ALLOGRAFT SURVIVAL
}

\author{
JERRY Y. NIEDERKORN \\ Dallas, Texas
}

\begin{abstract}
SUMMARY
The unique paucity of $\mathrm{Ia}^{+}$Langerhans cells (LCs) in the central cornea contributes to the immunological privilege of corneal allografts. A variety of stimuli can induce the centripetal migration of peripheral LCs. At least one of these stimuli (i.e. latex bead instillation) induces interleukin-1 (IL-1) secretion by corneal cells which acts as a potent chemoattractant for LCs. Within 30 minutes of intracorneal injection of IL-1, centripetal migration of LCs can be detected. The presence of donor-derived LCs in corneal allografts doubles the incidence of rejection of fully allogeneic corneal allografts as well as MHC matched, multiple minor $H$ mismatched corneal allografts. Although the presence of donor-specific LCs greatly jeopardises corneal allograft survival, migration of host-derived LCs into corneal allografts does not appear to increase the risk of rejection.
\end{abstract}

Corneal transplantation is the oldest, most common and, arguably, the most successful form of solid tissue transplantation. In the United States alone, over 40000 corneal transplants are performed each year. ${ }^{1}$ Although some have questioned the validity of the proposition that corneal allografts are endowed with immunological privilege, results from animal studies have unequivocally demonstrated the unique privilege of orthotopic corneal allografts. ${ }^{2-4}$ Orthotopic corneal allografts exchanged between donors and hosts mismatched at the entire major histocompatibility complex (MHC) and multiple minor $\mathrm{H}$ loci survive indefinitely in approximately $50 \%$ of the hosts, yet orthotopic skin allografts in similar donor-host combinations invariably undergo rejection in $100 \%$ of the hosts. ${ }^{2-4}$ The immunological privilege of corneal allografts is even more dramatic in donor-host combinations involving disparity only at

Correspondence to: Jerry Y. Niederkorn, PhD, Department of Ophthalmology, University of Texas Southwestern Medical Center, Dallas, TX 75235-9057, USA.
MHC class II loci. Although MHC class II mismatched skin allografts are consistently rejected in virtually all of the hosts, less than $20 \%$ of MHC class II mismatched corneal allografts undergo rejection., ${ }^{4,5}$

Although there have been numerous theories to explain the extraordinary success of corneal allografts, the avascular nature of the graft bed clearly contributes to their immunological privilege. ${ }^{6,7}$ However, a large body of experimental data suggests that additional factors contribute to the immunological privilege of corneal allograft. ${ }^{6,7}$ Among these is the conspicuous absence of Langerhans cells (LCs) in the central region of the cornea that is normally used for transplantation.

The importance of donor-specific, bone-marrowderived antigen-presenting 'passenger cells' in provoking allograft rejection is widely appreciated. ${ }^{8}$ LCs are highly immunogenic passenger cells and can be found in a wide variety of epithelial tissues including the peripheral regions of the cornea. ${ }^{9}$ LCs can directly stimulate alloimmune responses by virtue of their dense expression of class II MHC alloantigens. Injection of as few as $10 \mathrm{LCs}$ is adequate for eliciting alloimmune cytotoxic $\mathrm{T}$ lymphocyte (CTL) responses in mice. ${ }^{10}$ By contrast, 1000 times as many keratinocytes are needed to elicit a comparable response in the same mouse model. ${ }^{10}$

Our laboratory has been attracted to the hypothesis that the immune privilege of corneal allografts is due in large part to the exclusion of LCs from the corneal epithelium normally used for keratoplasty. We reasoned, therefore, that immune privilege would be abolished in grafts prepared from corneas containing donor-specific LCs.

A variety of stimuli can induce the migration of LCs from the corneal/limbal regions into the central areas of the cornea. ${ }^{9}$ These stimuli include: topical application of contact sensitising agents, ${ }^{11}$ viral infections, ${ }^{12}$ bacterial infection, ${ }^{13}$ cauterisation, ${ }^{14}$ insertion of suture, ${ }^{15}$ and intracorneal injection of sterile latex beads. ${ }^{16}$ Unlike most of the stimuli that 
elicit centripetal migration of peripheral LCs, intracorneal instillation of sterile latex beads does not provoke neovascularisation or induce the migration of other inflammatory cells such as neutrophils. ${ }^{16}$

\section{WHAT IS THE STIMULUS FOR LATEX-BEAD- INDUCED MIGRATION OF LANGERHANS CELLS?}

The homogeneous nature of the latex-bead-induced infiltrate suggests that a chemoattractant is elaborated by the corneal epithelium. Following their deposition in shallow incisions in the corneal epithelium, latex beads are phagocytosed and can be seen within the corneal epithelium. ${ }^{16}$ The previous findings of Gery and co-workers ${ }^{17}$ indicating that phagocytosis of latex beads stimulated macrophages to elaborate interleukin-1 (IL-1) and the observation that IL-1 is a potent chemoattractant, led us to suspect that this cytokine was the stimulus that induced the centripetal migration of LCs into latex-bead-treated corneas. Instillation of either $1.0 \mu \mathrm{m}$ sterile latex beads or $1.0 \mu \mathrm{m}$ formalinkilled Staphylococcus aureus produced similar migration of LCs into the central cornea, which suggested that the stimulus for LC migration was not due to the chemical composition of the latex polymer but was instead a response to particulate antigen. ${ }^{18}$ In vitro studies demonstrated that phagocytosis of either latex beads or $S$. aureus stimulated a dramatic increase in the elaboration of IL-1 by corneal cells. ${ }^{18}$ Moreover, intracorneal injection of either human $\mathrm{IL}-1^{8}$ or murine rIL-1 ${ }^{19}$ produced swift centripetal migration of peripheral LCs, thereby confirming the chemotactic properties of IL-1 in inducing LC migration within the corneal epithelium.

A recent study by Asbell et al. ${ }^{19}$ suggested that in addition to IL-1, other cytokines can independently induce LC migration in the mouse cornea. Intracorneal injection of either IL-2, IL-1 $\beta$, tumour necrosis factoralpha (TNF- $\alpha$ ), IL-6 or interferon-alpha (IFN- $\alpha$ ) stimulated swift migration of LCs. By contrast, neither IL- $1 \alpha$, transforming growth factor-beta, interferongamma, nor granulocyte-monocyte colony stimulating factor produced chemotactic effects following intracorneal injection. Although corneal epithelial cells and keratocytes are known to produce IL- $1 \alpha,{ }^{20}$ it is not presently known whether other chemotactic cytokines are also produced by corneal cells. Therefore, the importance of the IL-2, IL-6 and IFN- $\alpha$ in eliciting LC migration under physiologically relevant conditions remains to be established.

\section{EFFECT OF DONOR-SPECIFIC LANGERHANS CELLS ON ORTHOTOPIC CORNEAL ALLOGRAFT SURVIVAL}

Using a well-characterised orthotopic corneal allograft model in the rat, we examined the effect of donor-derived LCs on corneal graft survival in the context of specific categories of histocompatibility antigens.

We and others have demonstrated that orthotopic corneal allografts involving mismatches at the entire $\mathrm{MHC}$ and multiple minor $\mathrm{H}$ loci undergo rejection in $50-60 \%$ of the hosts. ${ }^{2-4}$ The remaining $40-50 \%$ of grafts do not undergo rejection. However. if donor corneas are pretreated with latex beads prior to transplantation, the rejection rate climbs to $96 \%{ }^{2}$ Thus, the presence of donor-derived 'passenger LCs' abolishes immunological privilege, even if the grafts are placed onto avascular graft beds.

\section{Effect of Donor LCs on Corneal Allografts Mismatched only at Class I MHC Loci}

The effect of donor LCs in provoking alloimmune responses specific for MHC class I antigens was also examined in the same rat model. ${ }^{21}$ Unlike corneal allografts involving donor-host disparities at the entire MHC plus multiple minor $\mathrm{H}$ loci. MHC class I-disparate grafts underwent rejection in only $18 \%$ of the naive hosts. Surprisingly, the presence of donorspecific LCs did not abolish immune privilege because only $20 \%$ of the grafts pretreated with latex beads went on to reject (Table I). Although the MHC class I-disparate grafts were poorly immunogenic, they were highly antigenic since hosts preimmunised with skin grafts rejected $100 \%$ of the subsequent corneal grafts. Moreover, even grafts that had been clear for over 30 days underwent rejection if the hosts were immunised with donor-specific orthotopic skin grafts. ${ }^{21}$ Thus, the avascular graft bed can block the induction but not the expression of alloimmune responses to corneal allografts.

\section{Effect of Donor LCs on Corneal Allografts Mismatched only at Class II MHC Loci}

Because none of the cells of the cornea constitutively express MHC class II antigens. it is not surprising that corneal grafts mismatched with the host only at MHC class II are rarely rejected. ${ }^{4.5}$ However, hosts preimmunised with orthotopic skin grafts rejected subsequent LC-free, class II-disparate corneal allografts (Table II). This apparent contradiction was explained by the ease with which MHC class II antigen expression can be induced in the cornea by a

Table I. Effect of donor Langerhans cells on MHC class I-disparate corneal allografts ${ }^{\mathrm{a}}$

\begin{tabular}{llc}
\hline $\begin{array}{l}\text { First graft } \\
\text { day 0) }\end{array}$ & $\begin{array}{c}\text { Second graft } \\
\text { (day 30) }\end{array}$ & $\begin{array}{c}\text { \% corneal } \\
\text { graft rejection }\end{array}$ \\
\hline Cornea $\left(\mathrm{LC}^{-}\right)$ & None & 18 \\
Cornea $\left(\mathrm{LC}^{+}\right)$ & None & 20 \\
Skin & Cornea & 100 \\
Cornea $\left(\mathrm{LC}^{-}\right)$ & Skin & 10() \\
\hline
\end{tabular}

${ }^{\text {a }}$ ummarised from previously published studies. ${ }^{21}$ 
Table II. Effect of donor Langerhans cells on MHC class II-disparate corneal allografts ${ }^{\mathrm{a}}$

\begin{tabular}{llc}
\hline First graft & Second graft & \% rejection (second graft) \\
\hline Cornea $\left(\mathrm{LC}^{-}\right)$ & None & 0 \\
Cornea $\left(\mathrm{LC}^{+}\right)$ & None & 0 \\
Skin & Cornea $\left(\mathrm{LC}^{-}\right)$ & 100 \\
Cornea $\left(\mathrm{LC}^{+}\right)$ & Cornea $\left(\mathrm{LC}^{-}\right)$ & 80 \\
Cornea $\left(\mathrm{LC}^{-}\right)$ & Cornea $\left(\mathrm{LC}^{-}\right)$ & 0 \\
\hline
\end{tabular}

${ }^{a}$ Summarised from a previously published study.

variety of manipulations, including keratoplasty. In these studies, LC-free orthotopic corneal allografts were removed at 24 hour intervals and examined by immunofluorescence for class II MHC antigen expression. Within 24 hours of transplantation onto a naive host, $25 \%$ of the corneal epithelial cells expressed MHC class II antigens and, by day 7, $100 \%$ of the cells were positive. ${ }^{5}$ Antigen expression dissipated rapidly and by day 10 post-transplantation the corneal grafts had returned to their original class II-negative phenotype.

Additional experiments examined the fate of LCcontaining MHC class II-disparate grafts. Like LCfree corneal grafts, LC-containing corneal grafts were not rejected in the naive hosts. However, class II-disparate orthotopic corneal allografts transplanted to the contralateral eyes of the same hosts were invariably rejected, regardless of whether or not they contained donor-specific LCs. Moreover, rejection of the second graft did not jeopardise the survival of the initial LC-containing graft. We have proposed that the LCs in the initial LC-containing graft immunised the host. Since the surgery-induced expression of class II antigens is transient, the grafts became antigenically invisible by the time an alloimmune response was generated. However, subsequent grafts were promptly rejected due to their expression of class II antigens and the swift anamnestic alloimmune responses that ensued.

If this hypothesis were true, one would expect that the initial clear grafts would undergo rejection if they were induced to express class II antigens. This was confirmed by two independent experimental procedures. In the first experiment, the initial clear LCcontaining grafts were removed by trephination and re-transplanted into the original graft bed. All of

Table III. Effect of induced expression of MHC class II antigens in existing corneal allografts in DA.BDV hosts ${ }^{\mathrm{a}}$

\begin{tabular}{lll}
\hline Graft & rIFN $-\gamma(1000$ U/day $)$ & Fate of graft \\
\hline DA.MR & Day 30, 31 & Rejected, day 32 \\
DA.MR & Day 22, 23,24 & Rejected, day 27 \\
DA.MR & Day 22, 23, 24 & Rejected, day 25 \\
DA.MR & Day 33,34 & Rejected, day 35 \\
DA.BDV & Day 25, 26, 27 & Clear \\
DA.BDV & Day 25, 26, 27 & Clear \\
DA.BDV & Day 25, 26, 27 & Clear \\
DA.BDV & Day 25, 26,27 & Clear \\
\hline
\end{tabular}

DA.MR and DA.BDV are congenic rat strains that differ only at MHC class II loci.
Table IV. Effect of donor Langerhans cells on corneal allografts mismatched only at multiple minor $\mathrm{H}_{\text {loci }}{ }^{\mathrm{a}}$

\begin{tabular}{|c|c|}
\hline$\overline{\text { Graft }}$ & $\%$ rejection \\
\hline Cornea $\left(\mathrm{LC}^{-}\right)$ & 26 \\
\hline Cornea $\left(\mathrm{LC}^{+}\right)$ & 59 \\
\hline Cornea $\left(\mathrm{LC}^{-}\right)$(pre-immune host) ${ }^{\mathrm{b}}$ & 100 \\
\hline Cornea $\left(\mathrm{LC}^{+}\right)$(late latex bead treatment $)^{\mathrm{c}}$ & 10 \\
\hline
\end{tabular}

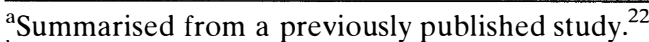

${ }^{\mathrm{b}}$ Hosts were pre-immunised with skin grafts from the same donor that provided the subsequent corneal allografts.

${ }^{c}$ Long-term surviving corneal grafts were treated with latex beads on day 60 post-transplantation. Grafts were observed for an additional 60 days. Only 1 of the 10 grafts underwent rejection by day 120 .

these grafts were promptly rejected. In a second experiment, class II antigen expression was induced by injecting rat $\mathrm{rIFN}-\gamma$ into LC-containing MHC class II-disparate corneal grafts that had remained clear for $>21$ days. All four of these grafts underwent rejection within 24-72 hours of rINF- $\gamma$ injection (Table III). By contrast, injection of rIFN- $\gamma$ into autografts did not elicit rejection or any discernible untoward effects. The results from these studies indicate that donor LCs render MHC class IIdisparate corneal grafts immunogenic but not antigenic. By contrast, surgery renders the grafts antigenic but not immunogenic since hosts bearing a LC-free corneal graft in one eye accept a second graft in the other eye as well.

\section{Effect of Donor LCs on Corneal Allografts Mismatched only at Multiple Minor H Loci}

Corneal grafts mismatched only at minor $\mathrm{H}$ loci enjoyed significant immunological privilege and were rejected in only $26 \%$ of the hosts. ${ }^{22}$ However, the presence of donor-specific LCs greatly diminished this immune privilege; rejection increased to $59 \%$ in hosts receiving LC-containing grafts (Table IV). The effect of host-derived LCs in promoting allograft rejection was evaluated in two ways. In one experiment $\mathrm{MHC}$ matched, multiple minor $\mathrm{H}$ mismatched corneal allografts that had remained clear for over 60 days were treated with sterile latex beads as a means of inducing the migration of host LCs. Nine of the 10 grafts treated in this manner remained clear for an additional 60 days, thereby indicating that infiltration of host-derived LCs did not jeopardise graft survival. A second experiment evaluated the infiltration of host-derived LCs as a result of the keratoplasty procedure itself. In these experiments, corneal allografts were removed at 24 hour intervals and assessed for infiltration of host LCs. Within 48 hours of grafting, large numbers of host-derived LCs were detected within the outer margins of the corneal graft. LCs continued to infiltrate the graft and were densely distributed throughout the entire graft. LCs remained for 2 weeks and gradually disappeared by the third week post-transplantation. These results indicate that, in 
the case of MHC matched, multiple minor $\mathrm{H}$ mismatched corneal grafts, donor LCs greatly increased the risk of rejection. By contrast, infiltration with host-derived LCs did not increase the risk of rejection of previously accepted cornea grafts.

\section{SUMMARY AND CONCLUSIONS}

The remarkable immunological privilege of corneal allografts is due, at least in part, to the unique exclusion of LCs from the central regions of the corneal epithelium. The distribution of LCs is dynamic and profoundly influenced by a variety of cytokines, most notably IL-1. Intracorneal injection of as little as 0.004 units of IL- 1 induces rapid centripetal migration of LCs that can be detected as early as 30 minutes after injection. ${ }^{18}$ The presence of donor-derived, but not recipient-derived, LCs renders some categories of corneal grafts highly immunogenic. In the case of MHC class II-disparate grafts, donor-specific LCs render the grafts immunogenic, yet not antigenic. By contrast, LC-free MHC class II-disparate grafts are not immunogenic but can be rendered highly antigenic through the surgeryinduced expression of MHC class II antigens. Hostderived LCs can be induced to enter long-term surviving corneal allografts, yet graft rejection does not necessarily ensue. Taken together, these results suggest that LCs exert a major effect in eliciting alloimmune responses via the direct pathway of antigen .presentation but do not appear to function effectively in alloantigen presentation through the indirect pathway.

Understanding the basis of the unique circumferential distribution of corneal LCs will undoubtedly yield important insights into the immunobiology of the cornea and dendritic antigen presenting cells as well. It seems plausible to expect that cornealderived cytokines play an important role in this cellular choreography.

These studies were supported in part by NIH Grant EY 07641 and an unrestricted grant from Research to Prevent Blindness, Inc., New York, N.Y.

Key words: Corneal allograft, Cytokine, Keratoplasty, Langerhans cells.

\section{REFERENCES}

1. The Collaborative Corneal Transplantation Studies Research Group. The collaborative corneal transplantation studies (CCTS). Effectiveness of histocompatibility matching in high-risk corneal transplantation. Arch Ophthalmol 1992;110:1392-403.

2. Callanan D, Peeler J, Niederkorn JY. Characteristics of rejection of orthotopic corneal allografts in the rat. Transplantation 1988;45:437-43.

3. Williams KA, Coster DJ. Penetrating corneal transplantation in the inbred rat: a new model. Invest Ophthalmol 1985;26:23-30.

4. Sonoda Y, Streilein JW. Orthotopic corneal transplantation in mice: evidence that the immunogenetic rules of rejection do not apply. Transplantation 1992;54:694-704.

5. Ross J, Callanan D, Kunz H, Niederkorn JY. Evidence that the fate of class II disparate corneal allografts is determined by the timing of class II expression. Transplantation 1991;51:532-6.

6. Niederkorn JY, Peeler JS. Regional differences in immune regulation: the immunogenic privilege of corneal allografts. Immunol Res 1988;7:247-55.

7. Niederkorn JY, Peeler JS, Ross J, Callanan D. The immunogenic privilege of corneal allografts. Regional Immunol 1989;2:117-24.

8. Austyn JM, Steinman RM. The passenger leukocyte: a fresh look. Transplant Rev 1988;2:139-76.

9. Jager MJ. Corneal Langerhans cells and ocular immunology. Regional Immunol 1992;4:186-95.

10. McKinney EC, Streilein JW. On the extraordinary capacity of allogeneic epidermal Langerhans cells to prime cytotoxic $\mathrm{T}$ cells in vivo. J Immunol 1989; 143:1560-4.

11. Roussel TJ, Osato MS, Wilhelmus KR. Corneal Langerhans cell migration following ocular contact hypersensitivity. Cornea 1983;2:27-30.

12. Asbell PA, Kamenar T. The response of Langerhans cells in the cornea to herpetic keratitis. Curr Eye Res 1987;6:179-82.

13. Hazlett LD, Moon MM, Dawisha S, Berk RS. Age alters ADPase positive dendritic (Langerhans) cell response to $P$. aeruginosa ocular challenge. Curr Eye Res 1986;5:343-55.

14. McLeish W, Rubsamen P, Atherton SA, Streilein JW. Immunobiology of Langerhans cells on the ocular surface. II. Role of central corneal Langerhans cells in stromal keratitis following experimental HSV-1 infection in mice. Reg Immunol 1989;2:236-43.

15. Lang RM, Friedlaender MH, Schoenrock BJ. A new morphologic manifestation of Langerhans cells in the guinea pig corneal transplants. Curr Eye Res 1981;1:161-7.

16. Peeler JS, Niederkorn JY. Antigen presentation by Langerhans cells in vivo: donor derived Ia+ Langerhans cells are required for induction of delayed-type hypersensitivity but not for cytotoxic $\mathrm{T}$ lymphocyte responses to alloantigens. J Immunol 1986; 136:4362-71.

17. Gery I, Davies P, Derr J, Krett N, Barranger JA. Relationship between production and release of lymphocyte-activating factor (interleukin-1) by murine macrophages. Cell Immunol 1981;64:293-303.

18. Niederkorn JY, Peeler JS, Mellon J. Phagocytosis of particulate antigens by corneal epithelial cells stimulates interleukin-1 secretion and migration of Langerhans cells into the central cornea. Regional Immunol 1989;2:83-90.

19. Asbell PA, Skittone LS, Epstein SP. Evaluation of chemotaxis by various cytokines of $\mathrm{Ia}^{+}$Langerhans cells into the corneas of $\mathrm{C} 3 \mathrm{H} / \mathrm{HeJ}$ mice. Invest Opthalmol Vis Sci (Suppl) 1994;35:1293.

20. Wilson SE, He YG, Lloyd SA. EGF, EGF receptor, basic FGF, TGF beta-1 and IL-1 alpha mRNA in human corneal epithelial cells and stromal fibroblasts. Invest Ophthalmol Vis Sci 1992;33:1756-65.

21. Ross J, He Y-G, Niederkorn JY. Class I disparate corneal grafts enjoy afferent but not efferent blockade of the immune response. Curr Eye Res 1991;10:889-92.

22. Ross J, He Y-G, Pidherney M, Mellon J, Niederkorn JY. The differential effects of donor versus host Langerhans cells in the rejection of MHC-matched corneal allografts. Transplantation 1991;52:857-61. 